Rendiconti Istituto Superiore di Sanità

Vol. 17. English edition. Pp. $x+243+46$ plates.

(Roma: Fondazione Emanuele Paterno; Oxford: Blackwell Scientific Publications, Ltd., 1954.) 5,000 lire; $57 s .6 d$.

THIS volume consists of twelve individual and largely unrelated contributions from different authors, each with a summary in English, French, German and Italian. Of these contributions, the majority comprise detailed descriptions of the construction and installation of fermentation vessels ranging in size from 10 to 300 litres capacity and adapted for fermentation research either in aerated or submerged culture. The remaining contributions include chapters on the interrelation of protein and polynucleotide synthesis in Escherichia coli, Romanoa - a new genus of antibacterial soil fungus-and two particularly interesting and topical papers by G. Sermonti on heterokaryosis in Penicillium chrysogenum.

The technological character of many of these papers must obviously limit the appeal of the volume as a whole. On the other hand, the detailed descriptions, maintenance, specifications and scale drawings of the apparatus described must equally ensure that anyone concerned with experimental fermentation plant will find the experience embodied in these papers invaluable. Many commonly encountered difficulties, such as turbulence, aeration and foaming, have been taken into account, but it must still be a matter for some regret that this lavish publication is likely, in respect of its technical sections, to become outdated within a comparatively short time as the special needs of research lead inevitably to modifications of small-scale fermentation apparatus. The scientific chapters form a group of original contributions in orthodox form, and these must secure a permanent place in scientific literature for the volume as a whole.

A. H. Cook

\section{Stability Theory of Differential Equations}

By Richard Bellman. (Intermational Series in Pure and Applied Mathematies.) Pp. xiii + 166. (London : McGraw-Hill Publishing Company, Ltd., 1953.) $44 s$.

THIS volume is introductory and elementary and the account is self-contained. It is a good text for the student about to begin research into stability theory. The style is attractive and does not suffer from the over-concentration so common in contemporary mathematical writing. Each chapter carries a number of exercises and there is a good bibliography, although there are not many references to the work published during the past five or six years.

The first chapter is concerned with the properties of linear systems. The necessary results in matrix theory are stated clearly, and the student unacquainted with the matrix calculus can read the account with ease. The main topic is the study of the asymptotic behaviour of the solutions of the equation $y^{\prime}=A y$, where $A$ is a constant matrix. In the second chapter the equation $z^{\prime}=[A+B(t)] z$ is considered, where the matrix $B(t)$ is, in some sense, small as $t \rightarrow \infty$. Stability, boundedness and asymptotic behaviour are investigated. Chapters 3 and 4 are concerned with non-linear systems. Two powerful methods are presented: (1) successive approximations, (2) approximation of the differential equations by difference equations. The results of
Poincaré and Liapounoff on stability are developed. Chapter 5 is a short one on the polynomial equation $P\left(t, u, u^{\prime}\right)=0$, and in Chapter 6 the well-known equation $u^{\prime \prime}+a(t) u=0$ is studied. The results are "a combination of ingenuity and special techniques". The last chapter concerns the Emden-Fowler equation $u^{\prime \prime} \pm t^{m} u^{n}=0$.

L. S. GODDARD

Mémoires sur la Théorie des Systèmes des Équations Différentielles Linéaires

Par J. A. Lappo-Danilevsky. Vols. 1, 2, 3 bound as one Volume. Pp. xiv $+253+208+204$. (New York: Chelsea Publishing Company, 1953.) 10 dollars.

TN 1931, J. A. Lappo-Danilevsky, a gifted young 1 Russian mathematician, died suddenly, leaving a great quantity of unpublished work. The Academy of Sciences of the U.S.S.R. made a careful study of this, and in 1933 began the publication in French of these three volumes, which incorporate both the published and unpublished work of Lappo-Danilevsky, with corrections and supplements where necessary. Apparently Western mathematicians took little notice of it until about twenty years later.

The subject of the work is the use of matrices for the discussion of a set of linear differential equations. It is true that this method had been previously used by others, including G. Peano, G. D. Birkhoff and H. F. Baker; but none of these seems to have treated the subject so fully and successfully as LappoDanilevsky. As a preliminary, he discusses functions of a matrix variable. His first application to differential equations is to a problem of Poincaré, obtaining results fuller than those of Poincaré himself. Other applications to differential and integral equations follow. There is a unity and naturalness about the work which is very attractive, though the extent of the preliminary theorems required makes the book by no means easy reading. H. T. H. PIAGGIo

\section{Metallurgy of Welding}

By Prof. Walter H. Bruckner. (Pitman Metallurgy Series.) Pp. xii + 290. (London: Sir Isaac Pitman and Sons, Ltd., 1954.) 30s. net.

THIS book gives $a$ useful and clearly illustrated account, although in rather a dull style, of the principles and practice of the various methods of welding, their metallurgical aspects, and details of the structure and properties of the metal in the weld region. The treatment includes discussion of heatflow in metals, considerations of residual stress, weldability, specifications and economic factors. In addition, the author deals with brazing, hard-facing, flame-hardening and metal-spraying.

A specific criticism, especially with respect to the chapter on metallic-are welding, is that the reader cannot always be sure whether the diseussion applies generally, or particularly, to steel. Further, there does not seem to be sufficient detailed and critical comparison of the merits of the various welding processes for specific metals, or of problems associated with particular metals. Another chapter, at least, is needed to discuss the welding of the major metals, separately.

It is generally assumed that the reader has a good background of metallurgical knowledge. Thus, engineers without such knowledge would need to consult first a text-book of engineering metallurgy. It must also be realized that this is an American book and refers predominantly to practice, specifications and literature in the United States.

A. R. Batley 